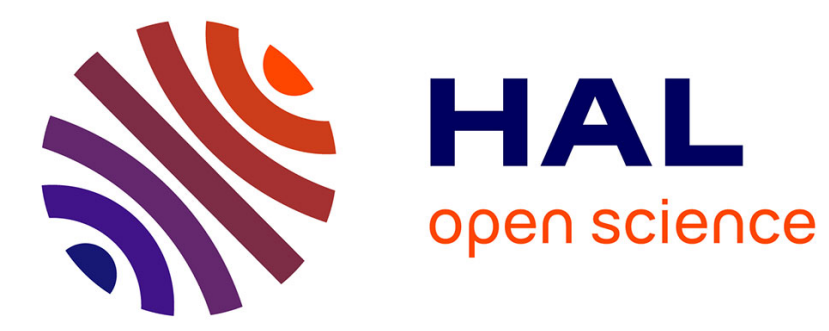

\title{
Changes in the firms behavior after the opening of markets of allowances
}

Antoine Mandel

\section{To cite this version:}

Antoine Mandel. Changes in the firms behavior after the opening of markets of allowances. Economic Theory, 2009, 40 (1), pp.1-25. 10.1007/s00199-008-0360-x . hal-00633355

\section{HAL Id: hal-00633355 https://hal.science/hal-00633355}

Submitted on 18 Oct 2011

HAL is a multi-disciplinary open access archive for the deposit and dissemination of scientific research documents, whether they are published or not. The documents may come from teaching and research institutions in France or abroad, or from public or private research centers.
L'archive ouverte pluridisciplinaire HAL, est destinée au dépôt et à la diffusion de documents scientifiques de niveau recherche, publiés ou non, émanant des établissements d'enseignement et de recherche français ou étrangers, des laboratoires publics ou privés. 


\title{
Changes in the Firms Behavior after the Opening of Markets of Allowances ${ }^{1}$
}

\author{
Antoine Mandel ${ }^{2} 3$ \\ Centre d'Economie de la Sorbonne, UMR 8174, CNRS-Université Paris 1. \\ 106-112 Bd de l'Hôpital 75013 Paris France
}

\begin{abstract}
This paper focuses on the influence of the opening of markets of allowances, such as the European Union Emission Trading Scheme, on the general equilibrium of an economy. Assuming there existed an equilibrium before the opening of these markets, we describe the changes in the firms behavior which guarantee that an equilibrium can be reached in the enlarged economy. Hence we describe under which conditions the economy can undergo the opening of markets of allowances.
\end{abstract}

Key Words: General Equilibrium Theory, Existence of Equilibrium, Externalities, Increasing Returns, Markets of allowances.

JEL Classification: C62, D21, D51, D62, Q54

\footnotetext{
$\overline{1}$ This paper is a substantial improvement of previous work in collaboration with Alexandrine Jamin (see (17)).

2 The author is grateful to Professor Jean-Marc Bonnisseau for his guidance and to an anonymous referee whose comments led to substantial improvements of the paper. All remaining errors are mine.

3 email:antoine.mandel@malix.univ-paris1.fr
} 


\section{Introduction}

This paper proposes a general equilibrium analysis of an economy undergoing the opening of markets of allowances. The motivation for such a study comes from the promotion of greenhouse gases emissions trading as a key instrument in climate change mitigation policies. A general equilibrium approach on the issue seems necessary because the amounts of trades on emission allowances markets may be large enough to influence the whole economy and because emission trading can difficultly be considered separately from the energy markets. Also, markets of allowances maintain close relationships with economic theory as their origin can be found in the Coase Theorem.

The previous general equilibrium literature (see Laffont (21), Boyd and al. (7), Conley and al. (11) ) has focused on the existence of equilibrium with markets of allowances, taking the presence of such markets as a fact. We put the emphasis on the effects of the creation of allowances' markets. The opening of new markets is a topic at the frontier of general equilibrium theory. Apart some recent contributions in the theory of incomplete markets (see Cass and al. (8) and Elul (14)), general equilibrium models usually consider the set of markets is fixed. This is emphasized by the assumption of market completeness or in the Schumpeterian analysis of economic evolution, (24), in which the opening of new markets is one of the dynamic phenomenon occurring in between, almost in opposition with, a sequence of general equilibria.

However, it seems to us that the actual creation of markets of allowances for greenhouse gases emissions, such as the European Union Emission Trading Scheme (EUETS), raises inevitably the question of the consequences of the opening of new markets on the existence of a general equilibrium. Taking into consideration the dynamical perspective imposed by the notion of creation of a market, we formulate our main interrogation as: "Which additional conditions ensure the existence of an equilibrium in an economy with markets of allowances knowing that there existed an equilibrium in the economy without such markets?"

Of course, such a question is relevant only when one can not apply the standard existence results (in our framework Bonnisseau-Cornet (3) and Jouini (18)) to the economy with allowances' markets. We argue this is the case. First it is unlikely that a global free-disposal assumption holds, because when it wastes part of its inputs a firm may incidentally pollute. Also, firms may suffer unbounded losses because of the cost of the allowances. Finally, as their markets are newly opened and as their "legal essence" make them differ from the other commodities, it seems disputable to posit directly assumptions on the agents characteristics in the economy enlarged with allowances.

Our analysis is conducted in a framework where the producers behavior is represented by general pricing rules. This allows us to encompass increasing 
returns to scale as well as competitive behavior. It seems important to encompass both cases as many of the firms subject to the greenhouse gases emissions reduction schemes are in the energy sector where the presence of increasing returns is commonly recognized and also because marginal pollution may well be decreasing. On another hand, pricing rules provide a convenient tool to represent changes in the firms behavior, after a slight change of perspective on their interpretation. They are not seen as the local counterpart of a general principle such as profit maximization or marginal pricing but rather as a set of constraints on the acceptable prices determining locally the firms behavior. Concerning the consumption side of the economy, the main particularity of our model is that agents may face a negative external effect because of the firms' pollution. They can purchase allowances as a public good in order to prevent it.

Our approach to prove the existence of an equilibrium is to posit separately assumptions on the initial functioning of the economy and on the changes in the firms' behavior following the opening of the allowances' markets. First, we use standard sufficient assumptions (see (3) and (18)) to ensure the existence of an equilibrium in the initial economy. Second we give conditions on the changes in the firms behavior which ensure that a gradual increase in the allowances' price leads to a general equilibrium for arbitrary initial endowments in allowances. Accordingly, our results link the range of initial endowments in allowances for which there exists an equilibrium with the flexibility and the sensitivity of the pricing rules with regards to the price of the allowances. Meanwhile we provide a contribution to the theory of general equilibrium with increasing returns as we indeed prove existence of equilibrium without some of the standard assumptions such as free-disposability, bounded losses or positive values of the pricing rules (see Jouini (19) and Giraud (16)).

\section{The Model}

\subsection{Initial economy}

We consider an initial economy ${ }^{4}$ with a finite number $L$ of commodities labeled by $\ell=1, \ldots, L, n$ firms indexed by $j=1, \ldots, n$ and $m$ consumers indexed by $i=1, \ldots, m$. This economy is lying within an environment whose state is described by a vector of $E$ real parameters $\tau \in \mathbb{R}_{-}^{E}$. The state of the environment (for example the atmospheric concentrations of various greenhouse

\footnotetext{
${ }_{4}$ Notations: in the latter, $R_{++}^{L}$ denotes the positive orthant of $R^{L}, R_{+}^{L}$ its closure, $S$ the simplex of $\mathbb{R}^{L}, S_{++}$its relative interior and $\mathcal{H}$ the affine space it spans. Also $e$ denotes the vector $\left(\frac{1}{L}, \ldots, \frac{1}{L}\right)$ of $\mathbb{R}^{L} . \mathcal{A} X$ denotes the asymptotic cone to the set $X$.
} 
gases) is altered by the production process and influences the consumers welfare. We focus on a situation where markets of allowances for environmental damages emerge whereas firms were used to pollute freely. Our aim is to study how the firms should then actualize their behavior in order to let a new general equilibrium come out. We formalize the situation as follows:

The production possibilities of firms in terms of 1 to $L$ commodities are described by sets $Y_{j}$ such that:

\section{Assumption (Initial Production IP) For all $j$,}

(1) $Y_{j}$ is closed;

(2) $0 \in Y_{j}$;

(3) $Y_{j}-\mathbb{R}_{+}^{L} \subset Y_{j}$;

(4) If , $\left(y_{j}\right) \in \prod_{j=1}^{n} \mathcal{A} Y_{j}$ and $\sum_{j=1}^{n} y_{j} \geq 0$ then for all $j, y_{j}=0$.

Those assumptions are standard and ensure that, inaction is possible for every firm, firms can freely-dispose of commodities ${ }^{5}$, free-production is impossible asymptotically.

As they produce, firms influence the environment. We measure according to the function $f_{j}: \mathbb{R}^{L} \rightarrow \mathbb{R}_{-}^{E}$ the minimal damage caused to the environment by firm $j$ (we speak of minimal damage because firms may be inefficient and pollute more than what they actually need to). The actual state of the environment when the firms choose a production scheme $\left(y_{j}\right) \in \prod_{j=1}^{n} Y_{j}$ is at least as bad as $\sum_{j=1}^{n} f_{j}\left(y_{j}\right)$ (the state of the environment is getting worse as this parameter decreases). We assume that the pollution function satisfies the following requirements:

Assumption (Pollution Function PF) For all $j, f_{j}: \mathbb{R}^{L} \rightarrow \mathbb{R}_{-}^{E}$ is differentiable, has values in $\mathbb{R}_{-}^{E}$ and satisfies $f_{j}(0)=0$

In the initial economy, the environment has no economic value so that the commodities' price is the only relevant variable for the firms. We let each firm determine its production's choices according to a pricing rule $\phi_{j}: \partial Y_{j} \rightarrow R_{+}^{L}$. That is the price $p \in \mathbb{R}_{+}^{L}$ of the commodities 1 to $L$, is acceptable for firm $j$ given a production plan $y_{j} \in Y_{j}$ if $p \in \phi_{j}\left(y_{j}\right)$. Such a behavior coincide with profit maximization when the $Y_{j}$ are convex and $\phi_{j}$ is the normal cone to $Y_{j}$. We assume

\section{Assumption (Initial Pricing Rules IPR) For all $j$,}

(1) $\phi_{j}$ has a closed graph.

$\overline{5}$ Under this assumption, according to Lemma 5 in Bonnisseau-Cornet (3), $\partial Y_{j}$ can be endowed with a manifold structure by homeomorphism with $e^{\perp}$. In the latter we will consider that this identification holds. 
(2) For all $y_{j} \in \partial Y_{j}, \phi_{j}\left(y_{j}\right)$ is a non-empty closed convex cone of $\mathbb{R}_{+}^{L}$ different of $\{0\}$.

Concerning the consumers, they gain utility from the consumption of nonnegative quantities of commodities 1 to $L$ and also are sensitive to the state of the environment. Their preferences are represented by an utility function $u_{i}$ defined on $\mathbb{R}_{+}^{L} \times \mathbb{R}^{E}$ which associates to a bundle, $x \in \mathbb{R}_{+}^{L}$, of commodities and to an environmental parameter $\tau \in \mathbb{R}^{E}$, an utility level $u_{i}(x, \tau)$. Their wealth comes from an initial endowment in commodities, $\omega_{i} \in \mathbb{R}_{++}^{L}$ (we let $\left.\omega=\sum_{i=1}^{m} \omega_{i}\right)$ and from an amount $r_{i}\left(\pi_{1}, \ldots, \pi_{n}\right)$ of the firms' profits and losses $\left(\pi_{1}, \ldots, \pi_{n}\right)$. The private property case where each agent $i$ holds a share $\theta_{i, j}$ in firm $j$ profits is encompassed in this setting and will serve as a benchmark. Those characteristics are assumed to satisfy the following assumptions:

Assumption (C) For all i,

(1) $u_{i}$ is quasi-concave and $C^{1}$ on $\mathbb{R}_{++}^{L} \times \mathbb{R}^{E}$;

(2) $u_{i}$ is monotonic;

(3) $\forall \tau \in \mathbb{R}_{-}^{E} \forall x \in \mathbb{R}_{+}^{L} \forall v \in \mathbb{R}_{+}^{L} \backslash\{0\} \exists k \geq 0$ such that $u_{i}(x+k v, \tau)>u_{i}(x, 0)$;

(4) $\omega_{i} \in \mathbb{R}_{++}^{L}$;

(5) $r_{i}: \mathbb{R}^{L} \rightarrow \mathbb{R}$ is continuous and $\sum_{i=1}^{m} r_{i}\left(\pi_{1}, \ldots, \pi_{n}\right)=\sum_{j=1}^{n} \pi_{j}$.

All those assumptions are standard but $C(3)$ which guarantees that a large enough increase in the consumption of any commodity can always compensate the deterioration of the environment.

The consumers behavior is then determined by the prices $p \in \mathbb{R}_{+}^{L}$ of the commodities 1 to $L$ as they maximize the utility they gain from consumption of those commodities, under their budget constraint and taking the state of the environment as given.

We can then define an equilibrium of the initial economy as:

Definition 1 An equilibrium of the initial economy is a collection $\left(\bar{p},\left(\bar{x}_{i}\right)\right.$, $\left.\left(\bar{y}_{j}, \bar{t}_{j}\right)\right)$ in $S_{++} \times\left(\mathbb{R}_{+}^{L}\right)^{m} \times \prod_{j=1}^{n}\left(Y_{j} \times \mathbb{R}_{-}^{E}\right)$ satisfying

(1) for every $i, \bar{x}_{i}$ maximizes $u_{i}\left(\cdot, \sum_{j=1}^{n} \bar{t}_{j}\right)$ in the budget set $B_{i}\left(\bar{p},\left(\bar{y}_{j}\right)\right):=\left\{x_{i} \in \mathbb{R}_{+}^{\ell} \mid \bar{p} \cdot x_{i} \leq \bar{p} \cdot w_{i}+r_{i}\left(\bar{p} \cdot \bar{y}_{j}\right)\right\} ;$

(2) for every $j, \bar{y}_{j} \in \partial Y_{j}, \bar{t}_{j} \leq f_{j}\left(\bar{y}_{j}\right)$ and $\bar{p} \in \phi_{j}\left(\bar{y}_{j}\right)$.

(3) $\sum_{i=1}^{m} \bar{x}_{i}=\sum_{j=1}^{n} \bar{y}_{j}+\sum_{i=1}^{m} w_{i}$.

In order to ensure that there exists such an equilibrium we posit standard sufficient assumptions for existence of equilibrium with general pricing rules (see (4), (18)).

On the one hand,we shall assume that the producers follow the marginal pricing rule or some pricing rule with bounded losses. 
Assumption (Initial Standard Pricing Rules ISPR) One of the following holds:

(1) For all $j, \phi_{j}$ has bounded losses: there exist $m_{j} \in \mathbb{R}$ such that if $\left(p, y_{j}\right) \in$ $S \times \partial Y_{j}$ and $p \in \phi_{j}\left(y_{j}\right)$, one has $p \cdot y_{j} \geq m_{j}$.

(2) For all $j, \phi_{j}$ is the marginal pricing rule given by Clarke's Normal cone to $Y_{j}$, that is $\phi_{j}\left(y_{j}\right)=N_{Y_{j}}\left(y_{j}\right)$ (see (10)).

On the other hand, a survival assumption must ensure that the economy produces enough wealth in a sufficiently large range of situations.

Assumption (Initial Survival IS) For all $\omega^{\prime} \geq \omega$, for all $\left(p,\left(y_{j}\right)\right) \in S \times$ $\prod_{j=1}^{n} Y_{j}$ such that $p \in \cap_{j} \phi_{j}\left(y_{j}\right)$ and $\sum_{j=1}^{n} y_{j}+\omega^{\prime} \geq 0$ one has $p \cdot\left(\sum_{j=1}^{n} y_{j}+\omega^{\prime}\right)>$ 0 .

Finally, in order to ensure each consumer receives a positive wealth, we posit:

Assumption (Initial Revenue IR) For all $\left(p,\left(y_{j}\right)\right) \in S \times \prod_{j=1}^{n} Y_{j}$ such that $\sum_{j=1}^{n} y_{j}+\sum_{i=1}^{m} \omega_{i} \geq 0$ and $p \cdot\left(\sum_{j=1}^{n} y_{j}+\sum_{i=1}^{m} \omega_{i}\right)>0$, one has for all $i$, $p \cdot \omega_{i}+r_{i}\left(p \cdot y_{j}\right)>0$.

Those assumptions guarantee the existence of an equilibrium in the initial economy in the sense of:

Theorem 1 Under Assumptions IP, PF, C, IPR, ISPR, IS and IR, there exist an equilibrium in the initial economy.

Proof: Cf Appendix. This is a consequence of the index formula we proved in (22), but could also be obtained as a corollary of Bonnisseau (5) and Bonnisseau-Médecin (6).

One can note that if the agents wealths are set according to a private property revenue scheme, the preceding assumptions clearly hold when the producers are competitive (i.e profit maximizers with convex production sets). More generally, they hold when the pricing rules are loss-free, i.e for all $\left(p, y_{j}\right) \in$ $S \times \partial Y_{j}$ such that $p \in \phi_{j}\left(y_{j}\right)$, one has $p \cdot y_{j} \geq 0$. This encompasses the case of marginal pricing rule when the production sets are star shaped with respect to 0 . Those particular cases are further discussed in the examples' section.

\section{Economies with markets of allowances}

Let us now consider that in order to limit the environmental damages due to production, the government introduces allowances for each environmental parameter and forces by legal means the firms to use as input in their production process a vector of allowances corresponding to their actual in- 
fluence on the environment. Namely, when firm $j$ deteriorates the environment of $t_{j} \in \mathbb{R}_{-}^{E}$ it must use as input a vector $-t_{j}$ of allowances. Meanwhile the government supplies allowances to the economy by initially allocating a vector $A \in \mathbb{R}_{+}^{E}$ of allowances to consumers and producers according to $a=\left(a_{1}, \cdots, a_{m}, a_{m+1}, \cdots, a_{m+n}\right) \in\left(\mathbb{R}^{E}\right)^{m+n}$ with $\sum_{i=1}^{m} a_{i}+\sum_{j=1}^{n} a_{j}=A$. The government hence limits the deterioration of the state of the environment to the level $-A$. Now, this initial allocation may not be efficient and agents may gain to trade allowances. Hence markets for allowances emerge. The agents should modify their behavior in order to adapt to the new market structure.

\subsection{Technical changes in the production sector}

First, the relevant production set for firm $j$ now is:

$$
Z_{j}:=\left\{\left(y_{j}, t_{j}\right) \in Y_{j} \times \mathbb{R}_{-}^{E} \mid t_{j} \leq f_{j}\left(y_{j}\right)\right\}
$$

Note that under Assumptions IP and PF, $Z_{j}$ is closed, contains 0 and satisfies asymptotically a no free-production condition. However, given our assumption on the pollution function, $Z_{j}$ does not necessarily satisfy a general freedisposability assumption of the type $Z_{j}-\mathbb{R}_{+}^{L+E} \subset Z_{j}$. Indeed firms may have to increase their use of allowances in order to dispose of their other inputs: for example when a firm burns its waste inputs it produces $\mathrm{CO}_{2}$ emissions as a by-product.

On another hand firms face an additional cost whose magnitude depend on the allowances' price $q$ : given a price $(p, q) \in \mathbb{R}^{L+E}$ and a production plan $\left(y_{j}, t_{j}\right) \in Z_{j}$ the profit of firm $j$ is $p \cdot y_{j}+q\left(a_{j}+t_{j}\right)$. Firms will consequently modify their pricing behavior. We shall denote by $\psi_{j}: \partial Z_{j} \rightarrow \mathbb{R}^{L+E}$ the pricing rule adopted by firm $j$ in the enlarged economy. Hence, the price vector $(p, q) \in R^{L+E}$ is acceptable for firm $j$ given the production plan $\left(y_{j}, t_{j}\right) \in \partial Z_{j}$ if and only if $(p, q) \in \psi_{j}\left(y_{j}, t_{j}\right)$.

\subsection{Changes in consumers behavior}

The changes which affect consumers characteristics are the modification of their consumption set ${ }^{6}$ which now is $\mathbb{R}_{+}^{L+E}$ and the modification of their revenue induced by the initial allocation of allowances and the changes in the firms profits. Given a production scheme $\left(y_{j}, t_{j}\right) \in \prod_{j=1}^{n} Z_{j}$ and a price

\footnotetext{
6 One should pay attention to the fact that even this enlarged consumption set is not the definition set of the utility function. Indeed the utility depends on the consumption of commodities $x_{i} \in \mathbb{R}_{+}^{L}$ and of the state of the environment which is a real parameter summarizing the external effects the consumer faces.
} 
$(p, q) \in \mathbb{R}^{L+E}$, the wealth distributed to consumer $i$ now is $(p, q) \cdot\left(\omega_{i}, a_{i}\right)+$ $r_{i}\left((p, q) \cdot\left(y_{j}, t_{j}+a_{j}\right)\right)$.

\subsubsection{Private use of the allowance}

Now the changes concerning properly the consumers' behavior depend on their access to the allowances' markets. If they do not have access to these markets as buyers, they behave as in the initial economy: given an environment $\tau$, they maximize the utility $u_{i}\left(x_{i}, \tau\right)$ they gain from consumption of bundles $x_{i} \in \mathbb{R}_{+}^{L}$ of commodities, under the budget constraint $p \cdot x_{i} \leq(p, q) \cdot\left(\omega_{i}, a_{i}\right)+r_{i}((p, q)$. $\left.\left(y_{j}, t_{j}+a_{j}\right)\right)$. In this case, the allowances are only used by firms and as private goods. Hence we can define an equilibrium with private use of allowances (denoted for short private equilibrium) as:

Definition 2 A private equilibrium of the enlarged economy is a collection $\left((\bar{p}, \bar{q}),\left(\bar{x}_{i}\right),\left(\bar{y}_{j}, \bar{t}_{j}\right)\right)$ in $\left(S^{L} \times \mathbb{R}_{+}^{E}\right) \times\left(\mathbb{R}^{L}\right)^{m} \times \prod_{j=1}^{n} \partial Z_{j}$ satisfying:

(1) for every $i, \bar{x}_{i}$ maximizes $u_{i}\left(\cdot, \sum_{j=1}^{n} \bar{t}_{j}\right)$ in the budget set $B_{i}\left(\bar{p},\left(\bar{y}_{j}\right)\right):=\left\{x_{i} \in \mathbb{R}_{+}^{\ell} \mid \bar{p} \cdot x_{i} \leq(\bar{p}, \bar{q}) \cdot\left(\omega_{i}, a_{i}\right)+r_{i}\left((\bar{p}, \bar{q}) \cdot\left(\bar{y}_{j}, \bar{t}_{j}+a_{j}\right)\right)\right\} ;$

(2) for every $j,(\bar{p}, \bar{q}) \in \psi_{j}\left(\bar{y}_{j}, \bar{t}_{j}\right)$;

(3) $\sum_{i=1}^{m} \bar{x}_{i}=\sum_{j=1}^{n} \bar{y}_{j}+\sum_{i=1}^{m} w_{i}$;

(4) $\sum_{i=1}^{m} a_{i}+\sum_{j=1}^{n} a_{j}+\sum_{j=1}^{n} \bar{t}_{j}=0$.

One can remark that in this framework the equilibrium state of the environment is exogenously fixed by the government through the initial allocation of allowances at $A=\sum_{i=1}^{m} a_{i}+\sum_{j=1}^{n} a_{j}$. This initial allocation also has effects on the repartition of wealth as the freely allocated allowances finally acquire a value. One should note that private use of allowances is the situation which prevails in some markets of allowances such as the European Union Emission Trading Scheme.

\subsection{Public use of the allowance}

When the consumers access to the allowances' markets is unrestricted, they may purchase them in order to prevent their use by the producers and hence improve the state of the environment. Their purchases benefit the other consumers so that allowances turn out to be public goods. Namely, the utility of a consumption bundle $\left(x_{i}, s_{i}\right) \in \mathbb{R}_{+}^{L+E}$ for agent $i$ given the quantity of allowances $\sum_{i=1}^{m} a_{i}+\sum_{j=1}^{n} a_{j}$ initially endowed to the economy and the quantities $\left(s_{k}\right)_{k \neq i}$ purchased by the other consumers is $u_{i}\left(x_{i},-\left(\sum_{j=1}^{n} a_{j}+\sum_{i=1}^{m} a_{i}\right)+\right.$ $\left.\left(\sum_{k \neq i} s_{k}+s_{i}\right)\right)$. Given an environment $-\left(\sum_{j=1}^{n} a_{j}+\sum_{i=1}^{m} a_{i}\right)+\sum_{k \neq i} s_{k}$, consumer $i$ is set to maximize the utility of its consumption bundle $\left(x_{i}, s_{i}\right) \in \mathbb{R}_{+}^{L+E}$, under the budget constraint $p \cdot x_{i}+q \cdot s_{i} \leq(p, q) \cdot\left(\omega_{i}, a_{i}\right)+r_{i}\left((p, q) \cdot\left(y_{j}, t_{j}+a_{j}\right)\right)$. We then define an equilibrium with public use of allowances (denoted for short 
public equilibrium) as:

Definition 3 A public equilibrium of the enlarged economy is a collection $\left((\bar{p}, \bar{q}),\left(\bar{x}_{i}, \bar{s}_{i}\right),\left(\bar{y}_{j}, \bar{t}_{j}\right)\right)$ in $\left(S^{L} \times \mathbb{R}_{+}^{E}\right) \times\left(\mathbb{R}_{+}^{L+E}\right)^{m} \times \prod_{j=1}^{n} \partial Z_{j}$ satisfying:

(1) for every $i,\left(\bar{x}_{i}, \bar{s}_{i}\right)$ maximizes $u_{i}\left(x_{i},-\left(\sum_{j=1}^{n} a_{j}+\sum_{i=1}^{m} a_{i}\right)+\left(\sum_{k \neq i} s_{k}+s_{i}\right)\right)$ in the budget set $B_{i}\left(\bar{p},\left(\bar{y}_{j}\right)\right):=\left\{\left(x_{i}, s_{i}\right) \in \mathbb{R}_{+}^{L+E} \mid(\bar{p}, \bar{q}) \cdot\left(x_{i}, s_{i}\right) \leq(\bar{p}, \bar{q}) \cdot\right.$ $\left.\left(\omega_{i}, a_{i}\right)+r_{i}\left((\bar{p}, \bar{q}) \cdot\left(\bar{y}_{j}, \bar{t}_{j}+a_{j}\right)\right)\right\}$

(2) for every $j,(\bar{p}, \bar{q}) \in \psi_{j}\left(\bar{y}_{j}, \bar{t}_{j}\right)$;

(3) $\sum_{i=1}^{m} \bar{x}_{i}=\sum_{j=1}^{n} \bar{y}_{j}+\sum_{i=1}^{m} w_{i}$;

(4) $\sum_{i=1}^{m} \bar{s}_{i}=\sum_{j=1}^{n} \bar{t}_{j}+\sum_{i=1}^{m} a_{i}+\sum_{j=1}^{n} a_{j}$.

At such an equilibrium, the state of the environment is endogenously determined and depends of each consumer's purchase of allowances as public goods. The initial allocation of allowances still influences the repartition of wealth.

\section{Changes in the firms behavior and existence of equilibrium.}

The existence of an equilibrium in the enlarged economy relies heavily on the modification of the firms behavior following the opening of the allowances' markets. Indeed, the producers may consider they can only handle small variation of the quantity of pollution they cause so that an equilibrium will fail to exist if the initial allocation of allowances is too low. Also, firms may undergo important losses because of the cost of the allowances as inputs. This may lead the revenue of certain consumers below 0 and hence prevent the existence of an equilibrium.

If one wanted to use standard existence theorems to discard those failures, one would have to posit assumptions equivalent to those made in the initial economy (see (5), (6), (22)) . That is:

Assumption ( $\left.\mathbf{P}^{\prime}\right)$ For all $j, Z_{j}$ is closed, $0 \in Z_{j}, Z_{j}-\mathbb{R}_{+}^{L+E} \subset Z_{j}$ and if $\left(z_{j}\right) \in \prod_{j=1}^{n} \mathcal{A} Z_{j}$ and $\sum_{j=1}^{n} z_{j} \geq 0$ then for all $j, z_{j}=0$.

Assumption (PR') For all $j, \psi_{j}$ has a closed graph and for all $z_{j} \in \partial Z_{j}$, $\psi_{j}\left(z_{j}\right)$ is a non-empty closed convex cone of $\mathbb{R}_{+}^{L+E}$ different of $\{0\}$.

Assumption (BL') For all $j, \psi_{j}$ has bounded losses or coincide with the marginal pricing rule.

Assumption (SA') For all $\left(\omega^{\prime}, A^{\prime}\right) \geq(\omega, A)$ for all $\left((p, q)\left(z_{j}\right)\right) \in S \times$ $\prod_{j=1}^{n} Z_{j}$ such that $(p, q) \in \cap_{j} \phi_{j}\left(z_{j}\right)$ and $\sum_{j=1}^{n} z_{j}+\left(\omega^{\prime}, A^{\prime}\right) \geq 0$ one has $(p, q)$. $\left(\sum_{j=1}^{n}\left(y_{j}, z_{j}\right)+\left(\omega^{\prime}, A^{\prime}\right)\right)>0$. 
Assumption (R') For all $\left((p, q)\left(z_{j}\right)\right) \in S \times \prod_{j=1}^{n} Z_{j}$ such that $(p, q) \cdot\left(\sum_{j=1}^{n}\left(y_{j}\right.\right.$, $\left.z_{j}\right)+\left(\omega^{\prime}, A\right)>0$, one has $(p, q) \cdot\left(\omega_{i}, a_{i}\right)+r_{i}\left((p, q) \cdot\left(y_{j}, t_{j}+a_{j}\right)\right)>0$.

However, one has already remarked that the free-disposal condition posited in $\mathrm{P}^{\prime}$ is likely to be violated in our framework. This implies that the pricing rules might not have positive values as required by assumption PR'. The bounded losses Assumption also is problematic since the cost of allowances used as inputs may prevent its satisfaction. Hence standard existence theorems may not be appropriate in our framework.

The alternative we propose is to use as a building block the existence of an equilibrium in the initial economy. We perturb the corresponding equilibrium correspondence proportionally to allowances' price, and then prove existence of equilibrium in the enlarged economy by showing "existence properties" are conserved for well-chosen perturbations. The use of this methodology allows to get rid of the assumptions above mentioned as problematic and to weaken most of the others but requires the introduction of three non-standard assumptions. Two of them, Compatibility and Flexibility, link via the pricing rules the behavior of the firms in the initial and enlarged economies. The other one, labeled Amenability, guarantee that the demand of firms in allowances will eventually decrease as the allowances' prices increase ; we shall prove below it is implied by bounded losses.

Those additional assumptions should be interpreted as conditions on the firms behavior (i.e on the pricing rules) which are sufficient to ensure existence of equilibrium in the enlarged economies, knowing that sufficient conditions for the existence of an equilibrium were satisfied in the initial economy.

\subsection{Stability of the initial equilibrium}

First, in order to remain in a workable framework we shall assume that the newly set pricing rule satisfy the regularity and homogeneity properties commonly used in the literature:

\section{Assumption (PR)}

For all $j, \psi_{j}$ has a closed graph and convex values in $\mathbb{R}^{L+E}$.

Note that we do not assume the enlarged pricing rules have positive values. Indeed, as mentioned above, the lack of free-disposability makes it doubtful that such a condition always holds. In particular, it is not necessarily satisfied in the case of marginal pricing (see the examples' section).

A second natural requirement concerns the compatibility of the firms behavior with the one it had in the initial economy: 


\section{Assumption (Compatibility)}

(1) $\forall y_{j} \in \partial Y_{j}$, one has $\left\{p \in \mathbb{R}^{L} \mid(p, 0) \in \psi_{j}\left(y_{j}, f_{j}\left(y_{j}\right)\right)\right\}=\phi_{j}\left(y_{j}\right)$

(2) $\forall\left(y_{j}, t_{j}\right) \in \partial Z_{j}, \forall(p, q) \in \psi_{j}\left(y_{j}, t_{j}\right)$ such that $q_{e}=0$, one has $(p, q) \in$ $\psi_{j}\left(y_{j}, u_{j}\right)$ for all $u_{j}$ such that ${ }^{7} u_{j, e}<t_{j, e}$.

The first part of this assumption states that when all the allowances' price are null it is from the firms point of view as if they were available in arbitrary high quantity, so that they can behave as in the initial economy. The second part accordingly states that in the enlarged economy when a given allowance has a null price, firms do not constrain themselves to use it efficiently.

Compatibility clearly implies that the equilibria of the initial economy coincide with the private equilibria of the enlarged economy with zero allowance price:

Lemma 1 Assume that for all $j, \psi_{j}$ satisfies Compatibility. Then $\left(\bar{p},\left(\bar{x}_{i}\right)\right.$, $\left.\left(\bar{y}_{j}, \bar{t}_{j}\right)\right)$ is an equilibrium of the initial economy if and only if there exist an allowance allocation $\left(\left(a_{i}\right),\left(a_{j}\right)\right) \in\left(\mathbb{R}^{E}\right)_{+}^{m+n}$ such that $\sum_{j=1}^{n} a_{j}+\sum_{i=1}^{m} a_{i}+$ $\sum_{j=1}^{n} \bar{t}_{j} \geq 0$ and $\left(\bar{p}, 0,\left(\bar{x}_{i}\right),\left(\bar{y}_{j}, \bar{t}_{j}\right)\right)$ is a private equilibrium of the enlarged economy.

As a corollary, under Compatibility there can exist equilibria with improved state of the environment (compared to the initial situation) only if firms are ready to accept positive prices for the allowance and to modify consequently their behavior. In this respect let us define:

Definition 4 An allowances' price $q \in \mathbb{R}_{+}^{E}$ is called acceptable for firm $j$ at $y_{j}$ if there exist $p \in S_{++}$such that $(p, q) \in \psi_{j}\left(y_{j}, f_{j}\left(y_{j}\right)\right)$. We shall denote by $Q_{j}\left(y_{j}\right)=\left\{q \in \mathbb{R}_{+}^{E} \mid \exists p \in S_{++}\right.$s.t $\left.(p, q) \in \psi_{j}\left(y_{j}, f_{j}\left(y_{j}\right)\right)\right\}$ the set of allowances' price acceptable for firm $j$ at $y_{j}$.

The compatibiilty assumption implies that $0 \in \mathbb{R}_{+}^{E}$ is an acceptable allowances' price. However Lemma 1 implies that if it were the only acceptable price there could not exist equilibria in the enlarged economy other then the embedding of the initial equilibria. One hence has to provide the possibility for the enlarged pricing rule to depart from the initial pricing rules. Rather than giving a quantitative bound on the suitable amount of flexibility, we introduce a more behavioral type of assumption which states that a firm is always ready to adapt locally its behavior to a change in the allowances' price. Namely, we assume:

Assumption (Flexibility) For all $j$, for all $y_{j} \in \partial Y_{j}$, the set $Q_{j}\left(y_{j}\right)$ is open in $\mathbb{R}_{+}^{E}$.

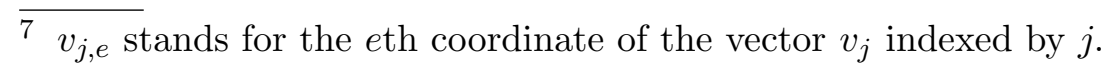


This assumption is satisfied, as well as Compatibility, in the case of marginal pricing (cf the examples Section) or when the behavior of the firm is determined by some function depending on the profit (e.g zero profit pricing rule). It can also be justified by assuming that the enlarged pricing rule is obtained by adding to the initial one perturbations proportional to the allowances' price, that is it is of the form $\psi_{j}\left(y_{j}\right)=\left\{\left(\phi_{j}\left(y_{j}\right)+\nu_{j}\left(q, y_{j}\right), q\right) \mid q \in \mathbb{R}_{+}\right\}$.

This flexibility requirement ensures existence of equilibrium is locally stable to the perturbation induced by the opening of the allowance market in the sense of:

Theorem 2 Under Assumptions IP, PF, C, IPR, IS, ISPR, IR, PR, Compatibility and Flexibility, there exists a neighborhood of zero in $\mathbb{R}_{+}^{E}$, $\mathcal{O}$, such that for every allowance price $q \in \mathcal{O}$, there exist an initial endowment in allowance $\left(\left(a_{i}\right),\left(a_{j}\right)\right) \in\left(\mathbb{R}_{+}^{E}\right)^{m+n}$ such that the enlarged economy has a private equilibrium with allowances' price equal to $q$.

\section{Proof: $\quad$ Cf Appendix. ${ }^{8}$}

The fact that the allowances' price turns positive does not necessarily imply that the state of the environment is improved. Indeed the initial allocation $\left(\left(a_{i}\right),\left(a_{j}\right)\right)$ given by the preceding Theorem may be constant for every $q \in \mathcal{O}$. In order to ensure the economy may undergo positive reductions of its use of allowances, one must impose further conditions on the influence of the allowances' price on the firms behavior.

\subsection{On the survival assumption in the enlarged economy}

A prerequisite therefore is to ensure that the economic activity remains viable even though the allowances' price increases significatively. The new costs induced by the use of allowances as inputs may lead the firms to use less productive technology for the production of commodities. In turn, this may modify the value of the outcome of the economic process. The economic activity as a whole remains viable only if this value remains positive. Mathematically, this comes to:

Assumption (SA) For all $\left((p, q),\left(y_{j}\right)\right) \in\left(S \times \mathbb{R}_{+}^{E}\right) \times \prod_{j=1}^{n} \partial Y_{j}$ such that $\sum_{j=1}^{n} y_{j}+\omega \geq 0$ and $(p, q) \in \cap_{j} \psi_{j}\left(y_{j}, f_{j}\left(y_{j}\right)\right)$ one has $p \cdot\left(\sum_{j=1}^{n} y_{j}+\omega\right)>0$.

This is a weak form of survival assumption as, contrary to Assumption IS and SA', it bears only on the set of attainable allocations. Hence it states that firms do not actually choose production plans such that the aggregate wealth is zero,

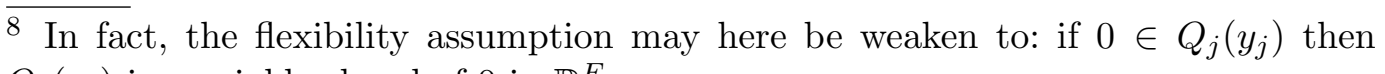
$Q_{j}\left(y_{j}\right)$ is a neighborhood of 0 in $\mathbb{R}_{+}^{E}$ 
whereas the usual survival assumptions (which bear on a larger set than this of attainable allocations) posit that the firms do not choose production plans which would, for even greater resources, lead to a null aggregate wealth. Also note that SA, oppositely to SA', concerns only the value of the production in terms of 1 to $L$ commodities. The allowances do not enter into consideration here, as at equilibrium no wealth is created or lost because of the operation of the allowances' markets. The working of these markets only causes lump-sum wealth transfers.

Now, assumption SA suffices to guarantee that whatever the allowances' price may be, the economic process is beneficial and hence a private equilibrium may be reached:

Theorem 3 Under Assumptions IP, C,PF, IPR, IS, ISPR, IR, PR, Compatibility, Flexibility and $S A$, for every non-negative allowance price $q$, there exist an initial endowment in allowance $\left(\left(a_{i}\right),\left(a_{j}\right)\right) \in\left(\mathbb{R}^{E}\right)^{m+n}$ such that the enlarged economy admits a private equilibrium with allowance price equal to $q$.

\section{Proof: Cf Appendix.}

Remark 1 Theorem 3 can be seen as a result of existence of equilibrium with fixed price of allowances. Existence of fixed price equilibria are usually obtained (see Drèze (13)) by fixing constraints on supply or demand in the economy. Here the constraints bear on the initial endowments in allowances.

Remark $2{ }^{9}$ Assumption SA can be obtained in some cases as a consequence of the initial survival assumption IS. Indeed, if one assumes that firms raise their output prices in order to compensate the costs of the allowances, then IS imply $S A$.

One can also guarantee assumption SA holds if there always exists an output whose price is positive. This can be seen as a consequence of a general raise of the output prices in order to compensate the cost of allowances.

Finally, because of the interiority of the initial endowments in commodities, it is clear that Assumption $S A$ holds as long as the enlarged pricing rules do not allow for losses on the commodities markets.

\subsection{On the revenue assumption in the enlarged economy}

Even-though they do not influence the aggregate wealth, transfers occurring on the allowances' markets matter because of their influence on the consumers revenue. Indeed, in order to ensure the existence of an equilibrium, one must guarantee that each consumer receive a positive part of the aggregate wealth.

$\overline{9}$ This discussion is further detailed in the working paper (23). 
This condition may fail to hold when the losses on the allowances' markets are not well distributed. In order to prevent this failure, one can extend the initial revenue assumption to:

Assumption (Revenue R) For all $\left((p, q),\left(y_{j}\right),\left(a_{i}, a_{j}\right)\right) \in\left(S \times \mathbb{R}_{+}^{E}\right) \times \prod_{j=1}^{n} Y_{j} \times$ $\left(\mathbb{R}_{+}^{E}\right)^{m+n}$ such that $(p, q) \in \cap_{j} \psi_{j}\left(y_{j}, f_{j}\left(y_{j}\right)\right)$, and $(p, q) \cdot\left(\sum_{j=1}^{n} y_{j}+\sum_{i=1}^{m} \omega_{i}, \sum_{j=1}^{n} a_{j}+\right.$ $\left.\sum_{i=1}^{m} a_{i}+\sum_{j=1}^{n} f_{j}\left(y_{j}\right)\right)>0$, one has for all $i(p, q) \cdot\left(\omega_{i}, a_{i}\right)+r_{i}\left((p, q) \cdot\left(y_{j}, a_{j}+\right.\right.$ $\left.f_{j}\left(y_{j}\right)\right)>0$.

This amounts to state there exists an appropriate mechanism of wealth transfer which allocates the firms losses on commodities and allowances' markets among consumers.

Note that the initial revenue assumption guaranteed the existence of such a mechanism for the standard commodities markets only, what is not sufficient to ensure each agent receives a positive wealth for arbitrary allocation of allowances. Indeed consider a firm which makes a zero profit on the 1 to $L$ commodities market and uses large quantities of allowances, it is going to support heavy losses when the allowances prices raise. An agent who owns a large share of this firm may see its revenue turn negative.

Nevertheless if the government targets precisely the needs of each firm in allowances so that there is no trade of allowances at equilibrium (that is one has for all $\left.j, a_{j}=-f_{j}\left(y_{j}\right)\right)$, then there are no losses on the allowances' markets and the initial revenue assumption is sufficient to ensure each consumer receives a positive wealth. Even tough it can be related to the principle of grandfathering, it is very demanding to consider the government is able to choose the initial allocations with such accuracy and foresight.

Remark 3 Nevertheless, if one wants to dispense with the enlarged revenue assumption, one can consider in the following that the government targets precisely the needs of each firm in allowances (that is one has for all $j, a_{j}=$ $-f_{j}\left(y_{j}\right)$ ). Our existence results (Theorems 4 and 5) then remain valid if one reads "for every aggregate level of allowances" (allocated so that there are no losses on the allowances markets) instead of "for every initial allocation of allowances."

\subsection{Existence of Private Equilibrium for arbitrary allowances' allocation}

Finally, in order to obtain equilibria for arbitrary allowances' allocations, the firms behavior must be amenable enough to the allowances' price. Hence we state, 


\section{Assumption (Amenability)}

For all $\epsilon>0$, for all $e \in\{1, \cdots, E\}$ there exist $K_{\epsilon} \geq 0$ such that for every equilibrium of the enlarged economy $\left(\left(\left(p, q_{-e}{ }^{10}\right), q_{e}\right),\left(y_{j}\right)\right) \in\left(S_{L+E-1} \times \mathbb{R}_{+}\right) \times$ $\prod_{j=1}^{n} Y_{j}$ one has for all $j, f_{j, e}\left(y_{j}\right) \geq-\epsilon$.

This assumption, states that when an allowance price is large enough, the only equilibrium production plans acceptable by the firms are those which generate an a priori fixed low level of the corresponding pollution. This is satisfied in particular when the enlarged pricing rules have bounded losses in the sense of assumption $\left(B L^{\prime}\right)$. Indeed, if Amenability does not hold, one can claim using Theorem 3 that for every $q \in \mathbb{R}_{+}$there exist an equilibrium at which at least one of the firms faces losses of the order of magnitude of $q \epsilon$ (as it actually purchases more than $\epsilon$ allowances at price $q$ while its profits on the other markets are bounded by compacity).

We can now state our main results on the existence of equilibrium for arbitrary initial allocations in allowances.

Theorem 4 Under Assumptions IP, PF, C, IPR, IS, ISPR, IR, PR, Compatibility, Flexibility, $S A, R$ and Amenatibility, for every initial allocation of allowance $\left(\left(a_{i}\right),\left(a_{j}\right)\right) \in\left(\mathbb{R}_{+}^{E}\right)^{m+n}$, the enlarged economy has an equilibrium with private use of allowances.

Proof: cf. Appendix

\subsection{Existence of Public equilibrium for arbitrary allowances' allocation}

We now turn to the existence of equilibrium with public use of the allowance. In this framework the demand in allowances of the consumers tends to push up the prices as soon as the markets open. Hence the analogous of Theorems 2 and 3 do not hold. However, one has:

Theorem 5 Under Assumptions IP, PF, C IPR, IS, ISPR, IR, Compatibility, Flexibility, $S A, R$ and Amenatibility, for every initial allocation of allowance $\left(\left(a_{i}\right),\left(a_{j}\right)\right) \in\left(\mathbb{R}_{+}^{E}\right)^{m+n}$, the enlarged economy has an equilibrium with public use of allowances.

Proof: Cf Appendix.

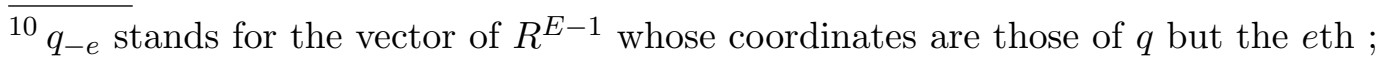
$f_{j, e}$ denotes the $e$ th coordinate function of $f_{j}$ 


\section{Examples}

We shall now discuss to which extent the results stated in the preceding sections apply to commonly used pricing rules.

\subsection{Business as usual}

In order to set a benchmark, let us first consider the Business as usual situation where firms do not modify their behavior following the opening of the allowances' markets and where consumers do not have access to these markets. That is firms keep following their initial pricing rule on the 1 to $L$ commodities market and then purchase the quantity of allowances they need whatever its price may be, while consumers are only affected by wealth transfers. In this framework all the previous assumptions but Amenability hold so that there exist equilibria for every allowances' price. However these equilibria in fact coincide with those one can obtain in the initial economy after a revenue redistribution and hence require a corresponding supply of allowances. In particular the state of the environment is not improved.

\subsection{Global Loss Free}

Let us now focus on the case where pricing rules are globally loss-free in the sense of:

Assumption (Global Loss Free) For all $j$, for all $y_{j} \in \partial Y_{j}$, for all $(p, q) \in$ $\psi_{j}\left(y_{j}, f_{j}\left(y_{j}\right)\right), p \cdot y_{j}+q f_{j}\left(y_{j}\right) \geq 0$,

then Assumption SA holds. Moreover Amenatibility clearly holds because the use of a positive fixed quantity of any allowance for arbitrary high price would entail losses. Hence one obtains using Theorems 4 and 5 :

Corollary 1 Under Assumptions IP, PF, C,IPR, IS, ISPR, IR, PR, Compatibility, Flexibility, (Global Loss Free) and $R$, for every initial allocation of allowance $\left(\left(a_{i}\right),\left(a_{j}\right)\right) \in \mathbb{R}_{+}^{m+n}$, the enlarged economy has an equilibrium with public (resp. private use) of allowances.

Note that this encompasses in particular the case of competitive behavior when the $Y_{j}$ are convex sets containing zero and the pollution functions are concave. That is to say when the marginal returns are decreasing and the marginal pollution is increasing. 


\subsection{Marginal Pricing and Competitive Behavior}

Let us now deal with the case of marginal pricing behavior. That is we consider the firms follow the marginal pricing rule given by Clarke's Normal cone (see (10)) in the initial and in the enlarged economy. This also encompasses the case of competitive behavior when the production sets are convex.

We restrict attention to the case where the marginal pricing rule is loss-free in the initial economy, that is we shall posit

Assumption (Star-Shaped) For all $j, Y_{j}$ is 0-star-shaped.

We shall also assume that the pollution increases with the scale of production:

Assumption (Increasing Pollution) For all $\left(y_{j}\right) \in \prod_{j=1}^{n} Y_{j}$ such that $\sum_{j=1}^{n} y_{j}+\omega \geq 0$ (and $\left.f_{j, e}\left(y_{j}\right)<0\right)$ the application $\mu \rightarrow f_{j, e}\left(\mu y_{j}\right)$ is (strictly) decreasing.

Finally, we assume that there exist an input whose use does not diminish any pollution ( what is fairly natural as the use of additional inputs is likely to increase pollution). In differentiable terms, the assumption may be stated as:

Assumption (Input Increase) For all $j$, for all $y_{j} \in Y_{j}$, one has for all $\lambda \in \mathbb{R}_{+}^{E}, \lambda^{\prime} D f_{j}\left(y_{j}\right) \notin \mathbb{R}_{--}^{L}{ }^{11}$

This suffices to guarantee the existence of a marginal pricing equilibrium.

Corollary 2 Under Assumptions IP,PF, C, (Star-Shaped), (Increasing Pollution), (Input Increase) and $R$, if each firm follows the marginal pricing rule then for every initial allocation of allowance $\left(\left(a_{i}\right),\left(a_{j}\right)\right) \in \mathbb{R}_{+}^{m+n}$, the enlarged economy has a public (resp a private) equilibrium.

Proof: The marginal pricing rule in the initial economy is given by

$$
\phi_{j}\left(y_{j}\right)=N_{Y_{j}}\left(y_{j}\right)
$$

and satisfies Assumptions IPR and ISPR.

As mentioned above (Star-Shaped) implies the marginal pricing rule is loss-free in the initial economy. Together with the interiority of the initial endowments this ensures the satisfaction of Assumptions IS and IR and the existence of a marginal pricing equilibrium in the initial economy according to Theorem 1.

Now, in the enlarged economy, the marginal pricing rule is given by (see Clarke

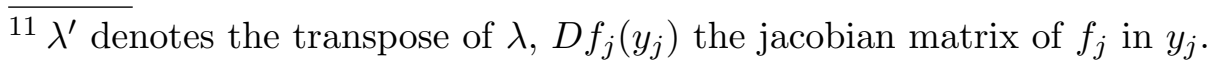


(10)):

$$
\psi_{j}\left(y_{j}, t_{j}\right)=\left(N_{Y_{j}}\left(y_{j}\right), 0\right)-\left\{\left(\lambda^{\prime} D f_{j}\left(y_{j}\right), \lambda\right) \mid \lambda \in \mathbb{R}_{+}^{E}, \lambda_{e}=0 \text { if } t_{j, e}<f_{j, e}\left(y_{j}\right)\right\}
$$

and satisfies Assumption $P R$ as well as Compatibility.

Differentiating (Increasing Pollution) one has for all $\left(y_{j}\right) \in \prod_{j=1}^{n} Y_{j}$ such that $\sum_{j=1}^{n} y_{j}+\omega \geq 0$, for all $\lambda \in \mathbb{R}_{+}^{E}, \lambda^{\prime} D f_{j}\left(y_{j}\right) \cdot y_{j} \leq 0$. As the initial pricing rules are loss-free because of (Star-Shaped), this implies the enlarged pricing rules do not entail losses on the 1 to L commodities' markets. Using then the interiority condition $C(4)$, we can affirm that assumption $S A$ holds.

On another hand (Input Increase) implies that whenever $p \in S_{++}$and $(p, \lambda) \in$ $\psi_{j}\left(y_{j}\right)$, there exist $p_{0} \neq 0$ in $N_{Y_{j}}\left(y_{j}\right) \cap \mathbb{R}_{+}^{L}$ such that $p=p_{0}-\lambda^{\prime} D f_{j}\left(y_{j}\right)$. Hence for $\epsilon>-\lambda$ small enough there exist $\mu:=\frac{1+(\lambda+\epsilon)^{\prime} D f_{j}\left(y_{j}\right) \cdot e}{p_{0} \cdot e} \geq 0$ such that $p^{\epsilon}=\mu p_{0}-(\lambda+\epsilon)^{\prime} D f_{j}\left(y_{j}\right) \in S_{++}$, so that $\left(p^{\epsilon}, \lambda+\epsilon\right) \in \psi_{j}\left(y_{j}\right)$ and $\lambda+\epsilon \in Q_{j}\left(y_{j}\right)$. Therefore, Flexibility holds.

Finally, let us focus on the Amenatibility requirement. Let us consider $\epsilon>0$ and $\left(y_{j}\right) \in \prod_{j=1}^{n} Y_{j}$ such that $\sum_{j=1}^{n} y_{j}+\omega \geq 0$ and $f_{j, e}\left(y_{j}\right) \leq-\epsilon$. Due to the compacity of the set of attainable production allocation ${ }^{12}$, AT, one has:

- $m=\sup \left\{\nabla f_{j, e}\left(y_{j}\right) \cdot y_{j} \mid\left(y_{j}\right) \in A T \inf _{j} f_{j, e}\left(y_{j}\right) \leq-\epsilon\right\}<0$, thanks to the differentiation of (Increasing Pollution)

- The set $\sup \left\{\sum_{j=1}^{n}\left\|y_{j}\right\|_{1} \mid\left(y_{j}\right) \in A T\right\}$ is bounded above and we denote by $M$ its least upper bound.

Let $\lambda^{e} \geq-\frac{2 M}{m}$. Now, assume there exist $p \in S_{++}$and $\lambda_{-e} \in \mathbb{R}_{+}^{E-1}$ such that $(p, \lambda) \in \psi_{j}\left(y_{j}, f_{j}\left(y_{j}\right)\right)$. One has $p+\lambda^{\prime} D f_{j}\left(y_{j}\right) \in N_{Y_{j}}\left(y_{j}\right)$, but $\left(p+\lambda^{\prime} D f_{j}\left(y_{j}\right)\right)$. $y_{j} \leq M+\lambda^{e} m<0$ which contradicts the fact that the marginal pricing rule on $Y_{j}$ is loss-free. Hence the Amenatibility Assumption holds.

All the necessary assumptions for Theorems 4 and 5 hold. It suffices to apply those results to end the proof.

Similar results hold for arbitrary pricing rules whenever the (Star-Shaped) Assumption is replaced by the assumption that the initial pricing rules $\phi_{j}$ are loss free and when the pricing rules of the enlarged economy are obtained by adding the marginal cost of the allowance used as input in the production process to the initial pricing rules. Namely, one has:

Corollary 3 Assume Assumptions IP,C, PF, IPR, (Increasing Pollution) and (Input Increase) hold. If the initial pricing rules $\phi_{j}$ are loss-free and the

$\overline{12}$ See the Appendix, section "Equilibrium Correspondence" for a proper definition. 
pricing rules in the enlarged economy are of the form

$$
\psi_{j}\left(y_{j}, t_{j}\right)=\left(\phi_{j}\left(y_{j}\right), 0\right)-\left\{\left(\lambda^{\prime} D f_{j}\left(y_{j}\right), \lambda\right) \mid \lambda \in \mathbb{R}_{+}^{E}, \lambda_{e}=0 \text { if } t_{j, e}<f_{j, e}\left(y_{j}\right)\right\},
$$

then for every initial allocation of allowance $\left(\left(a_{i}\right),\left(a_{j}\right)\right) \in \mathbb{R}_{+}^{m+n}$, the enlarged economy has a public (resp a private) equilibrium.

\section{Appendix, proofs}

\subsection{Foreword}

In order to prove existence of an equilibrium in the enlarged economy we can not use the seminal literature on increasing returns (among others (3) and (18)) because of the presence of externalities, the lack of free-disposability in the production process, the value of the enlarged pricing rules outside the positive orthant (e.g in the case of marginal pricing), and also because losses on the allowances' markets may be unbounded. Nevertheless it is easy to obtain an existence result in the initial economy. Our approach then is to perturb the equilibrium correspondence of the initial economy in a way such that new zeroes correspond to equilibria of the enlarged economies. We then use invariance properties of the degree (see Cellina (9)) in order to show that there actually exist such equilibria.

\subsection{Characterization of consumers behavior}

Let us first define the consumers demand. We consider the demand of agent $i$ in the enlarged economy when the allowances' consumption is restricted at a certain level $H \in \mathbb{R}_{+}^{E}$ :

Definition 5 The demand of agent $i, \Delta_{i}^{H}: \mathbb{R}_{-}^{E} \times\left(S_{++} \times\right]-1,+\infty\left[{ }^{E} \times \mathbb{R}_{+} \rightarrow\right.$ $\mathbb{R}^{L+E}$, is the correspondence which associates to a collection $(\tau,(p, q), w)$ of environment, prices and wealth the set of elements:

$\Delta_{i}^{H}(\tau,(p, q), w)=\left\{\left(\bar{x}_{i}, \bar{s}_{i}\right) \in \mathbb{R}_{+}^{L} \times \prod_{e=1}^{E}\left[0, H_{e}\right] \mid u_{i}\left(\bar{x}_{i}, \tau+\bar{s}_{i}\right)=\max _{B_{i}((p, q), w)} u_{i}\left(x_{i}, \tau+s_{i}\right)\right\}$

where $B_{i}((p, q), w)=\left\{\left(x_{i}, s_{i}\right) \in \mathbb{R}_{+}^{L} \times \prod_{e=1}^{E}\left[0, H_{e}\right] \mid p \cdot x_{i}+q \cdot s_{i} \leq w\right\}$.

The restriction of allowances' consumption below $H$ is a technical trick to be able to deal simultaneously with public and private use of allowances. In particular when $H=0, \Delta_{i}^{0}$ is the consumer demand in the initial economy and at a private equilibrium. This restriction also makes it licit to define the 
demand for negative allowances' prices. The use of negative allowances' prices also is a technical trick which ensure that the equilibria with zero allowances' price do not lie on the boundary of the domain of the equilibrium correspondence. Under assumption $C$, Berge's maximum Theorem ensures that $\Delta_{i}^{H}$ is non-empty valued and upper-semi-continuous (u.s.c). Moreover thanks to Assumption $\mathrm{C}(3)$ it satisfies the following boundary condition:

For all $\tau$, for all $\left(\left(p^{n}, q^{n}\right), w^{n}\right)$ converging to $(p, q, w)$ such that $w>0$ and $p \in \partial S$ one has for all $i, \lim _{n} \| \operatorname{proj}_{\mathbb{R}^{L}}\left(\left(\Delta_{i}^{H}\left(\tau,\left(p^{n}, q^{n}\right), w_{n}\right)\right) \|=+\infty\right.$.

The wealth of agent i, given prices $(p, q) \in(S \times]-1,+\infty\left[^{E}\right)$, production choices $\left(y_{j}\right) \in \prod_{j=1}^{n} Y_{j}$ and an initial allocation $\left(\left(a_{i}\right),\left(a_{j}\right)\right) \in \mathbb{R}_{+}^{n+m}$ of allowances is

$$
w_{i}\left((p, q),\left(y_{j}\right),\left(a_{i}\right),\left(a_{j}\right)\right)=(p, q) \cdot\left(\omega_{i}, a_{i}\right)+r_{i}\left((p, q) \cdot\left(y_{j}, f_{j}\left(y_{j}\right)+a_{j}\right)\right) .
$$

As this wealth may fail to be positive at some point we introduce following Lemma 2 in Jouini (18) auxiliary income functions, in order to be able to define the equilibrium correspondence on a sufficiently large set.

Lemma 2 Let $V=\left\{\left((p, q),\left(y_{j}\right),\left(a_{i}\right),\left(a_{j}\right)\right) \in S_{++} \times\right]-1,+\infty\left[{ }^{E}\right) \times \prod_{j=1}^{n} \partial Y_{j} \times$ $\left.\left(\mathbb{R}_{+}^{E}\right)^{m} \times\left(\mathbb{R}_{+}^{E}\right)^{n} \mid(p, q) \cdot\left(\sum_{j=1}^{n} y_{j}+\omega, \sum_{i=1}^{m} a_{i}+\sum_{j=1}^{n} a_{j}+\sum_{j=1}^{n} f_{j}\left(y_{j}\right)\right)>0\right\}$ there exist functions $\tilde{r}_{i}: V \rightarrow \mathbb{R}$ such that for all $\left((p, q),\left(y_{j}\right),\left(a_{i}\right),\left(a_{j}\right)\right) \in V$,

(1) $\sum_{i=1}^{m} \tilde{r}_{i}\left((p, q),\left(y_{j}\right),\left(a_{i}\right),\left(a_{j}\right)\right)=(p, q) \cdot\left(\sum_{j=1}^{n}\left(y_{j}, a_{j}+f_{j}\left(y_{j}\right)\right)+\left(\omega, \sum_{i=1}^{m} a_{i}\right)\right)$;

(2) for all $i, \tilde{r}_{i}\left((p, q),\left(y_{j}\right),\left(a_{i}\right),\left(a_{j}\right)\right)>0$;

(3) if for all $i, w_{i}\left((p, q),\left(y_{j}\right),\left(a_{i}\right),\left(a_{j}\right)\right)>0$ then for all $i$, $w_{i}\left((p, q),\left(y_{j}\right),\left(a_{i}\right),\left(a_{j}\right)\right)=\tilde{r}_{i}\left((p, q),\left(y_{j}\right),\left(a_{i}\right),\left(a_{j}\right)\right)$.

Proof: It suffices to set following (18), for all $\left((p, q),\left(y_{j}\right),\left(a_{i}\right),\left(a_{j}\right)\right) \in V$ :

$$
\tilde{r}_{i}\left((p, q),\left(y_{j}\right),\left(a_{i}\right),\left(a_{j}\right)\right)=(1-\theta(w)) \frac{\sum_{i=1}^{m} w_{i}}{m}+\theta(w) w_{i}
$$

where $w=\left(w_{i}\right)=w_{i}\left((p, q),\left(y_{j}\right),\left(a_{i}\right),\left(a_{j}\right)\right)$

and $\theta(w)=\left\{\begin{array}{cl}1, \quad & \text { if for all } i \quad w_{i}>0 \\ \frac{\sum_{i=1}^{m} w_{i}}{\sum_{i=1}^{m} w_{i}-m \inf _{i} w_{i}}, & \text { otherwise }\end{array}\right.$

\subsection{Proof of Theorem 1}

We can characterize the equilibria of the initial economy through the correspondence $E_{0}$ defined on $\left\{\left(p,\left(x_{i}\right),\left(y_{j}\right)\right) \in S_{++} \times\left(\mathbb{R}^{L}\right)^{m} \times \prod_{j=1}^{n} \partial Y_{j} \mid p\right.$. 
$\left.\left(\sum_{j=1}^{n} y_{j}+\sum_{i=1}^{m} \omega_{i}\right)>0\right\}$ by $E_{0}\left(p,\left(y_{j}\right)\right)=$

$$
\left(\begin{array}{c}
\left(\operatorname{proj}_{e^{\perp}}\left(\sum_{i=1}^{m} x_{i}-\sum_{j=1}^{n} y_{j}-\sum_{i=1}^{m} \omega_{i}\right),\right. \\
\left(x_{i}, 0\right)-\Delta_{i}^{0}\left(\sum_{j=1}^{n} f_{j}\left(y_{j}\right),(p, 0), \tilde{r}_{i}\left((p, 0),\left(y_{j}\right),(0),(0)\right),\right. \\
\left.\left(\bar{\phi}_{j}\left(y_{j}\right)-p\right)\right) .
\end{array}\right)
$$

where for all $j$ and all $y_{j} \in \partial Y_{j}, \bar{\phi}_{j}\left(y_{j}\right):=\phi_{j}\left(y_{j}\right) \cap S$.

It is a direct consequence of 4.3 in (22) and of the results of Jouini (18) that under Assumptions IP, PF, C, IPR, IS and IR the zeroes of $E_{0}$ coincide with the set of equilibria of the initial economy and that the degree of this correspondence is non-zero. Hence, there exist equilibria in the initial economy. This proves Theorem 1.

\subsection{Parametrization by the allowance market}

The opening of the allowances' markets influence the commodities' markets in two principal ways. First, the firms modify their pricing behavior in function of the allowances' price, second the consumers wealth is modified by the transfers taking place on the allowances' markets. Those influences might be represented as parameters influencing the equilibrium on the commodities' markets. Hence, we study in the following a parametrized equilibrium correspondence. The initial allocation of allowances for which there exist an equilibrium are then determined endogenously as the allocations which clear the allowances' markets for some values of the parameters.

The parameter influencing the firms pricing rules is the allowances' price. However, we would like to define parametrized pricing rules for every vector in $\mathbb{R}_{+}^{E}$ (even if this vector is not an admissible allowances' price for the firm). Therefore we have to use the following trick. We set for $\lambda \in \mathbb{R}_{+}^{E}$ and $y_{j} \in \partial Y_{j}$ :

- $\gamma_{j}\left(\lambda, y_{j}\right)=\sup ^{13}\left\{q \leq \lambda \mid \exists p \in S\right.$ s.t $\left.(p, q) \in \psi_{j}\left(y_{j}, f_{j}\left(y_{j}\right)\right)\right\}$

- $\bar{\phi}_{j}\left(\lambda, y_{j}\right)=\left\{p \in S \mid\left(p, \gamma_{j}\left(\lambda, y_{j}\right)\right) \in \psi_{j}\left(y_{j}, f_{j}\left(y_{j}\right)\right)\right\}$

- $\bar{\psi}_{j}\left(\lambda, y_{j}\right)=\left(\bar{\phi}_{j}\left(\lambda, y_{j}\right), \gamma_{j}\left(\lambda, y_{j}\right)\right)$.

The value of $\gamma_{j}\left(\lambda, y_{j}\right)$ coincide with the allowances' price whenever the pricing rule indeed admits $\lambda$ as a possible value for the allowances' price in $y_{j}$. Otherwise it is equal to the largest ${ }^{14}$ admissible allowances' price below $\lambda$. Such an element exists thanks to Assumption Compatibility and because $\psi_{j}$ has a

\footnotetext{
$\overline{13}$ This least upper bound is taken with regards to the lexicographic order on $\mathbb{R}_{+}^{E}$. ${ }^{14}$ cf 10 supra
} 
closed graph. The Assumption PR also implies that $\bar{\phi}_{j}$ and $\bar{\psi}_{j}$ are u.s.c with non-empty convex compact values.

Concerning the influence of the allowances' markets on the consumers wealth, one cannot represent it using the initial allocation of allowances as a parameter because this allocation must be endogenously determined. However at equilibrium the quantity of allowances used in the economy must be equal to the initial allocation. Hence in order to endogenize the wealth transfers taking place on the allowances markets, we implement fictious initial allocations in allowances as functions of the quantities of allowances used by the agents. Namely, we consider continuous mappings $\alpha:\left(\mathbb{R}^{E}\right)^{m+n} \rightarrow\left(\mathbb{R}^{E}\right)^{m+n}$ such that $\sum_{i=1}^{m} \alpha_{i}\left(\left(s_{i}\right),\left(t_{j}\right)\right)+\sum_{j=1}^{n} \alpha_{j}\left(\left(s_{i}\right),\left(t_{j}\right)\right) \equiv \sum_{i=1}^{m} s_{i}+\sum_{j=1}^{n} t_{j}$, and we interpret $\left(\alpha_{i}\left(s_{i}, t_{j}\right), \alpha_{j}\left(s_{i}, t_{j}\right)\right)$ as the quantity of allowances allocated to consumers and producers when $\left(\left(s_{i}\right),\left(t_{j}\right)\right)$ are the quantity of allowances used by producers and consumers respectively. Using such a representation, the demands $\left(x_{i}, s_{i}\right)$ of consumers correspond to a situation where the allowances' markets are (implicitly) cleared if and only if, $\left(x_{i}, s_{i}\right) \in \Delta_{i}^{H}\left(\sum_{j=1}^{n} f_{j}\left(y_{j}\right)-\right.$ $s_{i}, p, q, \tilde{r}_{i}\left((p, q),\left(y_{j}\right),\left(\alpha_{i}\left(f_{j}\left(y_{j}\right),\left(s_{i}\right)\right)\right),\left(\alpha_{j}\left(f_{j}\left(y_{j}\right),\left(s_{i}\right)\right)\right)\right)$. Indeed, agent $i$ usually makes its choice of allowances' consumption facing a situation where the quantity of allowances available for pollution (prior to its consumption) is $A-\sum_{h \neq i} s_{h}$. Here $A$ is unknown but one knows that whenever the allowances' markets are clear, $A$ is such that $A+\sum_{j=1}^{n} f_{j}\left(y_{j}\right)=\sum_{k=1}^{n} s_{k}$, so that $A-\sum_{h \neq i} s_{h}=\sum_{j=1}^{n} f_{j}\left(y_{j}\right)-s_{i}$. Hence one sets agent $i$ to make its choice of allowances' consumption facing a situation where the quantity of allowances available for pollution (prior to its consumption) is $\sum_{j=1}^{n} f_{j}\left(y_{j}\right)-s_{i}$. In the following, we shall abusively let $\Delta_{i}^{\alpha, H}\left((p, q),\left(y_{j}\right),\left(s_{i}\right)\right)$ stand for $\Delta_{i}^{H}\left(\sum_{j=1}^{n} f_{j}\left(y_{j}\right)-\right.$ $s_{i}, p, q, \tilde{r}_{i}\left((p, q),\left(y_{j}\right),\left(\alpha_{i}\left(f_{j}\left(y_{j}\right),\left(s_{i}\right)\right)\right),\left(\alpha_{j}\left(f_{j}\left(y_{j}\right),\left(s_{i}\right)\right)\right)\right)$.

\subsection{Equilibrium Correspondence}

Under Assumptions IP and C, the set of attainable commodities' allocations, $\left\{\left(\left(x_{i}\right),\left(y_{j}\right)\right) \in\left(\mathbb{R}_{+}^{L}\right)^{m} \times \prod_{j=1}^{n} Y_{j} \mid \sum_{i=1}^{m} y_{j}+\sum_{i=1}^{m} \omega_{i}=\sum_{i=1}^{m} x_{i}\right\}$ is compact. Hence there exist a compact ball $K$ of $R^{L}$ such that $K^{m+n}$ contains it in its interior. Let us set $U=\left\{\left((p, q),\left(x_{i}, s_{i}\right),\left(y_{j}\right)\right) \in\left(S_{++} \times\right]-1,+\infty\left[^{E}\right) \times(\operatorname{int}(K) \times\right.$ $\left.\left.\prod_{e=1}^{E}\right]-1, H_{e}+1[)^{m} \times \prod_{j=1}^{n} \partial Y_{j} \mid p \cdot\left(y_{j}+\omega\right)+q \cdot \sum_{i=1}^{m} s_{i}>0\right\}$,

We can now define an equilibrium correspondence parametrized by $(\alpha, \lambda, H)$ by setting: $F_{1}^{(\alpha, \lambda, H)}: U \rightarrow e^{\perp} \times \mathbb{R}^{E} \times\left(\mathbb{R}^{L+E}\right)^{m} \times\left(e^{\perp}\right)^{n}$ equal to

$\left(\operatorname{proj}_{e^{\perp}}\left(\sum_{i=1}^{m} x_{i}-\sum_{j=1}^{n} y_{j}-\omega\right), q-\lambda,\left(\Delta_{i}^{\alpha, H}\left((p, q),\left(y_{j}\right),\left(s_{i}\right)\right)-\left(x_{i}, s_{i}\right)\right), \bar{\phi}_{j}\left(\lambda, y_{j}\right)-p\right)$

$F_{1}$ is an equilibrium correspondence in the sense of the following lemma: 
Lemma 3 Assume IP, PF, C, IPR, IS, IR, PR Compatibility and Flexibility hold. Let $\left((p, q),\left(y_{j}\right),\left(x_{i}\right),\left(s_{i}\right)\right) \in\left(F_{1}^{(\alpha, \lambda, H)}\right)^{-1}(0,0,0,0)$, such that for all $i$, $w_{i}\left((p, q),\left(y_{j}\right), \alpha_{i}\left(f_{j}\left(y_{j}\right),\left(s_{i}\right)\right), \alpha_{j}\left(f_{j}\left(y_{j}\right), s_{i}\right)\right)>0$. One has:

(1) if $H=0,\left((p, q),\left(x_{i}\right),\left(y_{j}, f_{j}\left(y_{j}\right)\right)\right)$ is a private equilibrium for the initial allocation of allowances $\left(\alpha_{i}\left(f_{j}\left(y_{j}\right), 0\right), \alpha_{j}\left(f_{j}\left(y_{j}\right), 0\right)\right)$ with allowances' price $q=\lambda$.

(2) if for all $i \in\{1 \cdots m\}, s_{i}<{ }^{15} H,\left((p, q),\left(x_{i}, s_{i}\right),\left(y_{j}, f_{j}\left(y_{j}\right)\right)\right)$ is a public equilibrium for the initial allocation of allowances $\left(\alpha_{i}\left(f_{j}\left(y_{j}\right), s_{i}\right), \alpha_{j}\left(f_{j}\left(y_{j}\right), s_{i}\right)\right)$ with allowances' price $q=\lambda$.

Proof: Indeed let us consider $\left((p, q),\left(x_{i}, s_{i}\right),\left(y_{j}\right)\right) \in\left(F_{1}^{(\alpha, \lambda, H)}\right)^{-1}(0,0,0,0)$.

Let us first show that for all $j,(p, q) \in \psi_{j}\left(y_{j}, f_{j}\left(y_{j}\right)\right)$. First one clearly has $q=$ $\lambda \geq 0$ and hence $p \in \bar{\phi}_{j}\left(q, y_{j}\right)$. Assume $(p, q) \notin \psi_{j}\left(y_{j}, f_{j}\left(y_{j}\right)\right)$. Under Compatibility and $P R$, the only possibility is that ${ }^{16} q>_{\text {lex }} \gamma_{j}\left(q, y_{j}\right)$ and $\left(p, \gamma_{j}\left(q, y_{j}\right)\right) \in$ $\psi_{j}\left(y_{j}, f_{j}\left(y_{j}\right)\right)$. As $p \in S_{++}$, Assumption Flexibility then implies there exist $q_{1}$ such that $q>_{\text {lex }} q_{1}>_{\text {lex }} \gamma_{j}\left(q, y_{j}\right)$ and $\left(p, q_{1}\right) \in \psi_{j}\left(y_{j}, f_{j}\left(y_{j}\right)\right)$. This contradicts the definition of $\gamma_{j}\left(q, y_{j}\right)$. Hence one has $(p, q) \in \psi_{j}\left(y_{j}, f_{j}\left(y_{j}\right)\right)$.

As consumer $i$ demand of allowances is equal to $s_{i}$ and one always has $\sum_{i=1}^{m} \alpha_{i}$ $\left(f_{j}\left(y_{j}\right),\left(s_{i}\right)\right)+\sum_{j=1}^{n} \alpha_{j}\left(f_{j}\left(y_{j}\right),\left(s_{i}\right)\right)=\sum_{j=1}^{n} f_{j}\left(y_{j}\right)+\sum_{i=1}^{m} s_{i}$, the allowances markets are clear provided the initial allocation is equal to $\left(\alpha_{i}\left(f_{j}\left(y_{j}\right), s_{i}\right)\right.$, $\left.\alpha_{j}\left(f_{j}\left(y_{j}\right), s_{i}\right)\right)$.

Now, one has $\operatorname{proj}_{e^{\perp}}\left(\sum_{i=1}^{m} x_{i}-\sum_{j=1}^{n} y_{j}-\sum_{i=1}^{m} \omega_{i}\right)=0$. Walras law and clearance of the allowances markets then imply clearance of the 1 to $L$ commodities markets.

Moreover, as $w_{i}\left((p, q),\left(y_{j}\right), \alpha_{i}\left(f_{j}\left(y_{j}\right),\left(s_{i}\right)\right), \alpha_{j}\left(f_{j}\left(y_{j}\right), s_{i}\right)\right)>0$, the auxiliary incomes coincide with the original ones and hence the auxiliary demand coincide with the original demand of consumer $i$ when his consumption of allowances is restricted to be below $H$.

Finally, if $H=0$ the demand in allowances coincides with this at a private equilibrium of the economy.

If $s_{i}<H$, it coincides with this at a public equilibrium of the economy.

\subsection{Main Lemma}

The proofs of Theorems 2 to 5 are based on the following lemma which shows that the degree of $F_{1}$ can be related to the degree of the initial equilibrium

\footnotetext{
$\overline{15<\text { in }} \mathbb{R}^{E}$ refers to the strict inequality coordinatewise

${ }^{16}<_{\text {lex }}$ in $\mathbb{R}^{E}$ refers to the strict inequality for the lexicographic order
} 
correspondence. Indeed, given $(\alpha, \lambda, H)$ let us consider the family of correspondences $F_{t}^{(\alpha, \lambda, H)}: U \rightarrow e^{\perp} \times \mathbb{R}^{E} \times\left(\mathbb{R}^{L+E}\right)^{m} \times\left(e^{\perp}\right)^{n}$ defined by $\left(\operatorname{proj}_{e^{\perp}}\left(\sum_{i=1}^{m} x_{i}-\sum_{j=1}^{n} y_{j}-\omega\right), q-t \lambda,\left(\Delta_{i}^{\alpha, t H}\left((p, q),\left(y_{j}\right), s_{i}\right)-\left(x_{i}, s_{i}\right)\right), \bar{\phi}_{j}(t \lambda, y)-p\right)$

Now, it is clear that under Compatibility, $\left((p, q),\left(x_{i}, s_{i}\right),\left(y_{j}\right)\right) \in\left(F_{0}^{(\alpha, \lambda, H)}\right)^{-1}$ $(0,0,0,0)$ if and only if $q=0, s_{i}=0$ for all $i$ and $\left(p,\left(x_{i}\right),\left(y_{j}\right)\right)$ is a zero of $E_{0}$. Moreover it is clear that whatever may $(\alpha, \lambda, H)$ be the degree of $F_{0}^{(\alpha, \lambda, H)}$ is equal to this of $E_{0}$ and hence is non-zero according to the proof of Theorem 1.

Finally we show the degree of $F_{0}$ is equal to this of $F_{1}$.

Let us consider the following auxiliary survival assumption:

Assumption $\left(\mathbf{S A}^{\lambda}\right)$ For all $0 \leq \mu \leq \lambda$, for all $\left(p,\left(y_{j}\right)\right) \in S \times \prod_{j=1}^{n} \partial Y_{j}$ such that $\sum_{j=1}^{n} y_{j}+\omega \geq 0$ and $p \in \cap_{j} \bar{\phi}_{j}\left(\mu, y_{j}\right)$ one has $p \cdot\left(\sum_{j=1}^{n} y_{j}+\omega\right)>0$,

Lemma 4 Under Assumptions IP, PF,C,IPR, IS, ISPR, IR, PR, Compatibility, Flexibility and $\left(S A^{\lambda}\right)$,

$$
\operatorname{deg}\left(F_{0}^{(\alpha, \lambda, H)},(0,0,0,0)\right)=\operatorname{deg}\left(F_{1}^{(\alpha, \lambda, H)},(0,0,0,0)\right) .
$$

Proof: Let $\lambda$ such that $S A^{\lambda}$ holds. For sake of clarity let us denote $F_{t}$ instead of $F_{t}^{(\alpha, \lambda, H)}$. It is clear that $F_{t}$ defines an homotopy between $F_{0}$ and $F_{1}$. Let us show that the set $\cup_{t \in[0,1]} F_{t}^{-1}(0)$ is compact. The homotopy invariance property of the degree then implies the result (see (9)).

Indeed consider a sequence $\left(p^{n}, q^{n},\left(x_{i}^{n}, s_{i}^{n}\right),\left(y_{j}^{n}\right)\right) \in \cup_{t \in[0,1]} F_{t}^{-1}(0,0,0,0)$. For all $n$, there exist $t^{n}$ such that $F_{\left(t^{n}\right)}\left(p^{n}, q^{n},\left(x_{i}^{n}, s_{i}^{n}\right),\left(y_{j}^{n}\right)\right)=0$.

By construction the transfers on the allowances' markets are balanced. Hence, using Walras one obtains that $\sum_{i=1}^{m} x_{i}^{n}-\sum_{j=1}^{n} y_{j}^{n}-\omega=0$. Therefore for all $n,\left(\left(x_{i}^{n}\right),\left(y_{j}^{n}\right)\right)$ lies in the set of attainable allocations which is compact. Moreover one has $t^{n} \in[0,1], p^{n} \in S,(-1, \cdots,-1) \leq q^{n} \leq \lambda, s_{i}^{n} \in \prod_{e=1}^{E}\left[0, H_{e}\right]$. Hence $\left(t^{n},\left(x_{i}^{n}, s_{i}^{n}\right),\left(y_{j}^{n}\right), p^{n}, q^{n},\right)$ lie in a compact set and there exists a subsequence converging to $\left(t,\left(x_{i}, s_{i}\right),\left(y_{j}\right), p, q\right)$ where $t \in[0,1], x_{i} \in K$ and $s_{i} \in \prod_{e=1}^{E}\left[0, H_{e}\right], \sum_{j=1}^{n} y_{j}+\omega=\sum_{i=1}^{m} x_{i} \geq 0,(p, q) \in S \times\left[-1,+\infty\left[^{E}\right.\right.$.

It remains to show that $\left(p, q,\left(x_{i}, s_{i}\right),\left(y_{j}\right)\right) \in U$ and that $F_{t}\left(p, q,\left(x_{i}, s_{i}\right),\left(y_{j}\right)\right)=$ $(0,0,0,0)$.

First as $\left(\left(x_{i}\right),\left(y_{j}\right)\right)$ is an attainable allocation, one has $x_{i} \in \operatorname{int}(K)$.

Second as $\Delta_{i}^{H}$ has values in $\mathbb{R}^{L} \times \prod_{e=1}^{E}\left[0, H_{e}\right]$ it is clear that $s_{i} \in \prod_{e=1}^{E}\left[0, H_{e}\right] \subset$ $\left.\prod_{e=1}^{E}\right]-1, H_{e}+1[$. 
Third as $q=t \lambda \geq 0$ one clearly has $q>(-1, \cdots-1)$.

Fourth as $\bar{\phi}_{j}$ is u.s.c, one has, for all $j, p \in \bar{\phi}_{j}\left(t \lambda, y_{j}\right)$ and, as $\sum_{j=1}^{n} y_{j}+\omega \geq 0$, Assumption $S A^{\lambda}$ implies that $p \cdot\left(\sum_{j=1}^{n} y_{j}+\omega\right)>0$. Hence $\left(p, q,\left(y_{j}\right), \alpha_{i}\left(\left(f_{j}\left(y_{j}\right)\right)\right.\right.$, $\left.\left.\left(s_{i}\right)\right), \alpha_{j}\left(\left(f_{j}\left(y_{j}\right)\right),\left(s_{i}\right)\right)\right) \in V$. This implies the auxiliary individual income, $\tilde{r}_{i}$, all are strictly positive. Given the fact that $x_{i}^{n}$ is bounded, the boundary condition on the demand then implies that $p \in S_{++}$. This proves that $\left(p, q,\left(x_{i}, s_{i}\right),\left(y_{j}\right)\right) \in U$.

Given the continuity properties of correspondences $F_{t}$ and $\Delta_{i}$, one then has $\left(x_{i}, s_{i}\right) \in \Delta_{i}\left(p, q,\left(y_{j}\right), s_{i}\right)$ for all $i$ and $F_{t}\left(\left(y_{j}\right), p, q,\left(s_{i}\right)\right)=0$. This ends the proof.

\subsection{Proof of Theorem 2}

Given the compactness of the set of attainable allocations and the upper-semicontinuity of the pricing rules, it is clear that assumption $\mathrm{SA}^{\lambda}$ holds for all $\lambda$ in a neighborhood of zero. Hence one has according to Lemma 4 that for all $(\alpha, H)$ and for $\lambda$ in a neighborhood of zero, $\operatorname{deg}\left(F_{1}^{(\alpha, \lambda, H)}\right)$ is non-zero. Let us then set $\alpha_{j}\left(f_{j}\left(y_{j}\right),\left(s_{i}\right)\right)=f_{j}\left(y_{j}\right)$ and $\alpha_{i} \equiv 0$. For such an $\alpha$ Assumptions $\mathrm{SA}^{\lambda}$ and IR imply that for all $\left((p, q),\left(x_{i}, s_{i}\right),\left(y_{j}\right)\right) \in\left(F_{1}^{(\alpha, \lambda, H)}\right)^{-1}(0,0,0,0)$, one has $w_{i}\left((p, q),\left(y_{j}\right), \alpha_{i}\left(f_{j}\left(y_{j}\right),\left(s_{i}\right)\right), \alpha_{j}\left(f_{j}\left(y_{j}\right),\left(s_{i}\right)\right)>0\right.$. It then suffices to apply Lemma 3 to end the proof.

\subsection{Proof of Theorem 3}

Assumption $S A$ implies $S A^{\lambda}$ holds for all $\lambda \geq 0$. Hence one has according to Lemma 4 that for all $(\alpha, H)$ and for all $\lambda \geq 0, \operatorname{deg}\left(F_{1}^{(\alpha, \lambda, H)}\right)$ is non-zero. Now if one chooses $\alpha$ as in the proof of Theorem 2, it is clear that for all $\lambda$, for all $\left((p, q),\left(x_{i}, s_{i}\right),\left(y_{j}\right)\right) \in\left(F_{1}^{(\alpha, \lambda, H)}\right)^{-1}(0,0,0,0)$, one has $w_{i}\left((p, q),\left(y_{j}\right), \alpha_{i}\left(f_{j}\left(y_{j}\right)\right.\right.$, $\left.\left.\left(s_{i}\right)\right), \alpha_{j}\left(f_{j}\left(y_{j}\right), s_{i}\right)\right)>0$. It then suffices to apply Lemma 3 to end the proof.

\subsection{Extended Equilibrium set}

In addition to lemma 3, one has:

Lemma 5 If $\left.\left(t_{j, e}\right),\left(s_{i, e}\right), 0, z_{-e}\right)^{17} \in U$ is an equilibrium for an initial allocation $\left(\left(a_{i, e}\right)\left(a_{j, e}\right),\left(a_{-e, i}\right)\left(a_{-e, j}\right)\right)$, then for every $\left(c_{j}\right) \in \mathbb{R}_{+}^{n},\left(\left(t_{j, e}-c_{j}\right),\left(s_{i, e}\right), 0, z_{-e}\right)$

$\overline{17}$ We emphasize the coordinates relative to the eth allowance of an element $z \in U$ by writing such an element $z=\left(\left(t_{j, e}\right),\left(s_{i, e}\right),\left(q^{e}\right), z_{-e}\right)$ Also, we emphasize the initial allocation of allowance $e$ by writing $\left(\left(a_{i}\right)\left(a_{j}\right)\right)=\left(\left(a_{i, e}\right),\left(a_{j, e}\right),\left(a_{i,-e}\right),\left(a_{j,-e}\right)\right)$. 
$\in U$ is an equilibrium for each initial allocation $\left(\left(b_{i, e}\right),\left(b_{j, e}\right),\left(a_{i}^{-e}\right)\left(a_{j}^{-e}\right)\right)$ such that $\sum_{i=1}^{m} b_{i, e}+\sum_{j=1}^{n} b_{j, e}=\sum_{i=1}^{m} a_{i, e}+\sum_{j=1}^{n} a_{j, e}+\sum_{j=1}^{n} c_{j}$

Proof: The proof is straightforward using Amenability(ii) and noticing that when $q_{e}=0$, a change in the initial allocation of the eth allowance does not entail revenue changes.

Given a subset of equilibria $\mathcal{E}$, we shall denote by $C(\mathcal{E})$ the subset of equilibria hence extended. That is $C(\mathcal{E})=\mathcal{E} \cup\left(\cup_{e=1 \cdots E}\left\{\left(\left(u_{j, e}\right),\left(s_{i, e}\right), 0, z_{-e}\right) \in U \mid\right.\right.$ $\left.\left.\exists\left(\left(t_{j, e}\right),\left(s_{i, e}\right), 0, z_{-e}\right) \in \mathcal{E},\left(u_{j, e}\right) \leq\left(t_{j, e}\right)\right\}\right)$

\subsection{Proof of Theorem 4}

Let us show that there exist a private equilibrium for every initial endowment in allowance $\left(\left(a_{i}\right),\left(a_{j}\right)\right) \in\left(\mathbb{R}_{+}^{E}\right)^{n+m}$. Therefore, let us set :

- $\alpha_{i}\left(f_{j}\left(y_{j}\right),\left(s_{i}\right)\right)=\frac{a_{i}}{\sum_{i=1}^{m} a_{i}+\sum_{j=1}^{n} a_{j}}\left(\sum_{j=1}^{n} f_{j}\left(y_{j}\right)+\sum_{i=1}^{m} s_{i}\right)$

- $\alpha_{j}\left(f_{j}\left(y_{j}\right),\left(s_{i}\right)\right)=\frac{a_{j}}{\sum_{i=1}^{m} a_{i}+\sum_{j=1}^{n} a_{j}}\left(\sum_{j=1}^{n} f_{j}\left(y_{j}\right)+\sum_{i=1}^{m} s_{i}\right)$.

Under Assumption $\mathrm{R}$ and $\mathrm{SA}$ it is clear that for such an $\alpha$, for all $\lambda$, for all $\left((p, q),\left(x_{i}, s_{i}\right),\left(y_{j}\right)\right) \in\left(F_{1}^{(\alpha, \lambda, 0)}\right)^{-1}(0,0,0,0)$, one has $w_{i}\left((p, q),\left(y_{j}\right), \alpha_{i}\left(f_{j}\left(y_{j}\right)\right.\right.$, $\left.\left.\left(s_{i}\right)\right), \alpha_{j}\left(f_{j}\left(y_{j}\right), s_{i}\right)\right)>0$. So as in the proof of Theorem 3 there exist a private equilibrium for all non-negative allowances' price $\lambda$ with an initial allocation of allowances made according to $\alpha$, that is proportional to $\left(\left(a_{i}\right),\left(a_{j}\right)\right)$. It then remains to show that there exist an equilibrium with aggregate allowances supply exactly equal to $\sum_{i=1}^{m} a_{i}+\sum_{j=1}^{n} a_{j}$. Hence, in the following we consider only equilibria corresponding to initial allocations proportional to $\left(\left(a_{i}\right),\left(a_{j}\right)\right)$ and show that there indeed exist such equilibria for all aggregate allowances supply $A \in \mathbb{R}_{+}^{E}$.

More precisely, we shall show by recursion on the allowance index set $E$, the following property:

$\mathcal{P}_{e}$ : For all $e \in\{1, \cdots, E\}$ there exist equilibria for all aggregate allowance allocation $\left(A_{1}, \cdots, A_{e}\right) \in \mathbb{R}_{+}^{e}$ and for all allowances prices $q_{e+1}, \cdots q_{E} \in \mathbb{R}_{+}^{(E-e)}$

- Proof of $\mathcal{P}_{1}$.

Let a price for all allowances but the first $q_{-1} \in R_{+}^{E-1}$ be fixed. Let us then define the correspondence

$$
\mathcal{E}^{\alpha, 0, q_{-1}}\left(q_{1}\right)=C\left(\left\{z \in U \mid F_{1}^{\left(\alpha,\left(q_{-1}, q_{1}\right), 0\right)}(z)=0\right\}\right),
$$

Let $\bar{A}_{1}=\inf \left\{\sum_{j=1}^{n} f_{j, 1}^{18}(z) \in \mathbb{R}_{+} \mid z \in \mathcal{E}^{\alpha, 0, q^{-1}}(0)\right\}$. According to Theorem 3 and Lemma $5, \bar{A}_{1} \in \mathbb{R}$ and there exist equilibria for all $A_{1} \geq \bar{A}_{1}$.

$\overline{{ }^{18} \text { With }}$ a slight abuse of notation, given an equilibrium $z \in U$ and the corresponding 
On another hand, let $K_{\epsilon}$ be the bound associated by assumption Amenability to $\epsilon>0$ and $e=1$. According to theorem 3, there exist an equilibrium $z \in \mathcal{E}^{\alpha, 0, q_{-1}}\left(K_{\epsilon}\right)$. Such an equilibrium satisfies $\sum_{j=1}^{n} f_{j}^{1}(z) \leq \epsilon$ thanks to assumption Amenability and hence is an equilibrium for some $A_{\epsilon}^{1} \leq \epsilon$.

Now, the correspondence $\mathcal{E}^{\alpha, H, q^{-1}}: \mathbb{R}_{+} \rightarrow U$ is clearly upper semicontinuous thanks to the upper-semi-continuity of the pricing rules and of the demand correspondences. Therefore according to lemma 2 in (20), its graph is connected. Using connectedness of this graph of $E^{\alpha, 0, q_{-1}}$ and continuity of $\sum_{j=1}^{n} f_{j, 1}$, one has that $\sum_{j=1}^{n} f_{j}^{1}\left(G r a p h E^{\alpha, 0, q^{-1}}\right)$ is connected. Together with the preceding, this implies that there exist equilibria for all $A_{1}$ in $\left[A_{\epsilon}^{1},+\infty[\right.$.

- Proof of $\mathcal{P}_{e} \Rightarrow \mathcal{P}_{e+1}$

The proof proceeds as this of $\mathcal{P}_{1}$ using the fact that the correspondence

$$
\mathcal{E}^{\left(\alpha, H,\left(A_{1}, \cdots, A_{e}\right),\left(\bar{q}_{e+1}, \cdots, \bar{q}_{E}\right)\right.}: \mathbb{R}_{+} \rightarrow U
$$

defined by $\mathcal{E}_{e}^{\left.\alpha, H,\left(A_{1}, \cdots, A_{e}\right),\left(\bar{q}_{e+1}, \cdots, \bar{q}_{E}\right)\right)}\left(q_{e}\right)=$

$$
\begin{gathered}
C\left(\left\{z \in U \mid \exists\left(\tilde{q}_{1}, \cdots \tilde{q}_{e-1}\right) \in \mathbb{R}_{+}^{e-1}, F_{1}^{\left(\alpha,\left(\tilde{q}_{1}, \cdots \tilde{q}_{e-1}, q_{e}, \bar{q}_{e+1}, \cdots, \bar{q}_{E}\right), H\right)}(z)=0,\right.\right. \\
\left.\sum_{j=1}^{n} f_{j}^{1}(z)=A^{1}, \cdots, \sum_{j=1}^{n} f_{j}^{1}(z)=A^{e}\right\},
\end{gathered}
$$

has a connected graph.

To end the proof one just has to let $\epsilon$ tends towards zero.

\subsection{Proof of Theorem 5}

Applying the arguments of theorem 4 to the correspondences $F_{1}^{\alpha, \lambda, H}$, and to a $K_{\epsilon}$ chosen as the maximum between the bound on the allowance price associated to $\frac{\epsilon}{2}$ given by Assumption Amenability and the supremum on the set of attainable allocation of the agents marginal utility for the eth coordinate of the environment ${ }^{19}$, one can show that for all $H$, one has: for all initial allocation of allowances $\left(\left(a_{i}\right),\left(a_{j}\right)\right)$, there exist equilibria with allowance demand restricted below $H$.

However, for every $H$ such that $H>\sum_{i=1}^{m} a_{i}+\sum_{j=1}^{n} a_{j}$, it is clear that at such an equilibrium, each consumer demand in allowance is strictly less than $H$. One can then conclude using Lemma 3

equilibrium production $\left(y_{j}\right) \in \prod_{j=1}^{n} Y_{j}$, we let $\sum_{j=1}^{n} f_{j, 1}(z)$ stand for $\sum_{j=1}^{n} f_{j, 1}\left(y_{j}\right)$. The same convention apply to $\sum_{j=1}^{n} f_{j, e}$ below.

${ }^{19}$ Normalized such that the vectors of agents marginal utilities for the commodities lie in the simplex 


\section{References}

[1]

[2]

[3]

$[4]$

[5]

$[6]$

[7]

[8]

[9]

[10]

[11]

[12]

[13]

IPCC (2001) IPCC Third Assessment Report - Climate Change 2001

Arrow, K.J (1969) "The organization of economic activity : Issues pertinent to the Choice of Market versus Non-Market allocation", in Joint economic committee, The analysis and evaluation of Public Expenditures ; The PPB System, Washington DC : Government Printing Office, pp 47-64.

Bonnisseau, J-M. and Cornet, B. (1988) "Existence of equilibria when firms follow bounded losses pricing rules" Journal of Mathematical Economics, 1988, vol. 17, issue 2-3, pages 119147

Bonnisseau, J-M. (1992) "Existence of equilibria in the presence of increasing returns : A synthesis" J. Math. Econom. vol. 21(5), pp 441-452.

Bonnisseau, J-M. (1997) "Existence of Equilibria in Economies with Externalities and Nonconvexities. "Set-Valued Analysis, Volume 5, Number 3, pp. 209-226(18)

Bonnisseau, J-M. and Médecin, J-P (2001). " Existence of marginal pricing equilibria in economies with externalities and non-convexities." J. Math. Econom. 36, no. 4, 271-294.

Boyd, J. and Conley, John P. (1997) "Fundamental Nonconvexities in Arrovian Markets and a Coasian Solution to the Problem of Externalities" Journal of Economic Theory, Vol. 72, 1997, pp. 388-407.

Cass, D. and Citanna, A. (1998) "Pareto Improving Financial Innovation in Incomplete Markets," Economic Theory 11: 467494.

Cellina, A. and Lasota, A. (1969). - "A New Approach to the Definition of Topological Degree for Multivalued Mappings", Atti della Academia Nazionale dei Lincei, Rendiconti. Classe de Scienze Fisiche, Mathematiche e Naturali, 47, pp. 434-440. Clarke, F., 1983, "Optimization and nonsmooth analysis" (Wiley, New York).

Conley, J and Smith, S. (2005), "Coasian equilibrium," Journal of Mathematical Economics, vol. 41(6), pp 687-704

Dehez,P. and Drèze, J. (1988). "Competitive Equilibria with Quantity-taking Producers and Increasing Returns". JMathE; V.17, pp. 209-23

Drèze,J. (1975) "Existence of an Exchange Equilibrium under Price Rigidities", IER. 
[14] Elul, R., (1995) "Welfare Effects of Financial Innovation in Incomplete Markets Economies with Several Consumption Goods," Journal of Economic Theory 65: 43-7

[15] Guesnerie, R. (2003) (sous la direction de) "Kyoto et l'économie de l'effet de serre ", Conseil d'analyse économique $\mathrm{n}^{\circ} 39$, Paris, La Documentation française.

[16] Giraud, G. (2001) "An algebraic index theorem for nonsmooth economies" Journal of Mathematical Economics, V. 36( 4), pp. 255-269.

[17] Jamin,A. and Mandel,A. (2006) "A general equilibrium analysis of emission allowances." Cahiers de la Maison des Sciences Economiques, série bleue 2006.03.

[18] Jouini, E (1992) "An Index Theorem for Nonconvex Production Economies", Journal of Economic Theory, 57 (1), 176-196.

[19] Jouini, E (1992) "Existence of the equilibria without free disposal assumption", Economics Letters, 38, 37-42.

[20] Jouini, E (1993) "The graph of the Walras correspondence", Journal of Mathematical Economics, 22, 139-147.

[21] Laffont, J, J. (1978) Effets externes et théorie économique, Monographie du Séminaire d'économétrie. Centre National de la Recherche Scientifique, Paris.

[22] Mandel A. (2007) "An index theorem for production economies with externalities", Document de travail du Centre d'Economie de la Sorbonne 2007.26.

Mandel A. (2007) "Changes in the firms behavior after the opening of an allowance market", Document de travail du Centre d'Economie de la Sorbonne 2007.27.

Schumpeter, J. "Théorie de l'évolution économique Recherches sur le profit, le crédit, l'intérêt et le cycle de la conjoncture" Dalloz, Paris, 1999. 